\title{
Surveying housing market supply affordability using a spatial data mining approach
}

\author{
M. Argiolas \\ Department of Civil Engineering, Environment and Architecture, \\ University of Cagliari, Italy
}

\begin{abstract}
Over the last decade, a consistent increase in real-estate prices, both in Italy and others OECD member countries, has been registered. This rise in price and the following subprime mortgage scandal have resulted in a significant fluctuation in market prices and/or market activity and in a consequent spreading of concerns about future market trends. These factors and the actual economic crisis often preclude people from buying residential properties, especially for those who want to set up house for the first time. Considering the limited public purchasing power and the unemployment increase, social housing and other related public policies must be assisted by appropriate decision support systems in order to provide affordable housing solutions to local citizens in financial need. These systems need to be able to identify in which nationwide contexts it is necessary to act with more incisive determination. Such a need also has to be considered in terms of support for the local population in order to get a better awareness of real estate acquisition risks.

This work aims to analyse the general affordability level of residential properties in urban environments, through a spatial decision support system (SDSS). At present, the system is still in the development phase, but is able to generate a qualitative overview of the housing market supply, especially in those contexts where the acquired dataset is characterized by a suitable spatial density. Using this information, it is possible to assess the income level required to affordably meet the current housing market supply and compare it to the official average income registered within the area of study.
\end{abstract}

Keywords: housing affordability, spatial data mining, real estate appraisal, housing market, econometrics. 


\section{Introduction}

The growth of housing market prices recorded during these last ten years has generated a shared awareness of the significant decline in housing affordability registered among most of OECD countries [1]. Before the sub-prime scandal and the associated fall of real estate values, buying a house has generally been intended as a low risk investment. Today there is a different common perception on housing acquisition risks both in most of European nations and United States where, in 2012, the average recorded house price was forty per cent lower than five years before [2].

Nowadays, Italian citizens that have recently bought their home by signing bank loan, might face to a high investment risk. This risk is mainly due to both the unpredictable market future trend and the marketability of the property. After a housing purchase, if the householder's family economic condition is getting worse, re-converting a former use value into a market value may give rise to a significant capital loss. Obviously, this scenario is accentuated in regions that are suffer a strong economic crisis and cannot forecast an improvement in a short or middle term. Considering the current Italian economic recession and the increasing demand for job mobility, we can notice that this topic attract an increasing interest among bankers, economists and politicians. The last real estate report written by Italian Real Estate Market Observatory (OMI) and Italian Banking Association (ABI) is not as an encouraging forecast. In 2012, housing trades have suffered a direct collapse decreasing by $25.7 \%$ in 2011 , to quota 448,364 . This is the worst result since 1985, when were bought and sold about 430 thousand houses [3]. In reason of the past and current global occurrence of similar housing market conditions, subjects like affordable housing and sustainable development are currently considered strictly related and fundamental challenges for many countries around the world [4].

This work is based on a dataset that comes from a data mining application capable of detecting real estate housing offers, in order to determine their location and investigate them spatially. By analysing residential listings sales, it is possible to access to up to date information and define a spatial-temporal analysis of housing market selling list price trend. Moreover, the complementary use of spatial econometric approaches can lead to enhance the dataset reliability by analysing both spatial density (i.e. Kernel density) and correlation (i.e. Moran I). The intended final goal consists in defining a Spatial Decision Support System capable to analyse the spatial distribution of the average family available income required to purchase a home affordably. As one of the first applications of an early development stage of the SDSS, this study regards ten Italian metropolitan areas and analyses the relative conditions in which young families deal with a potential first home purchase that consists in an apartment with a living area of $55 \mathrm{~m}^{2}$. It is supposed that the difference between the detected offer price and market price is in line with national average of sixteen per cent, as confirmed by the recent report of the Bank of Italy [5]. This situation coincides, or is remarkably similar, to the one where a household decides, motivated by the growth of his family, to sell his 
apartment $\left(55 \mathrm{~m}^{2}\right)$ in order to buy another one with a living area of $110 \mathrm{~m}^{2}$, in the same market area.

Considering its potential use to optimize social housing policies, this approach also aims to be an additional reference point to enhance urban sustainability. The adopted approach fits perfectly in Openshaw's definition of user friendly Exploratory Spatial Data Analysis [6] and with the increasing appreciation on the complementary use of geographic information and communication technology in city planning and management [7].

In the following sections, it is described the applied methodology and the case of study. Finally, the discussion of the obtained results and final considerations about prospected future improvements of the system will close the study.

\section{Methodology}

The approach adopted in this paper is based on the use of two different complementary references. On one hand, a data-mining approach to acquire information concerning market offers is used, on the other hand, a macroeconomic index resulting from the relationship between housing market selling lists and the local community median income. Market offer price spatial analysis and the subsequent quantification of the level of affordability aim to assist SDSS users to understand what the effective possibilities to acquire a housing property in view of their economic condition are. In addition, the knowledge of this relationship can be particularly useful for surveying a specific housing market state. In fact, in ordinary cases, a widespread local difficulty in purchasing/renting real estate is generally a symptom of an inflated market that necessarily have to readjust itself through a reduction in prices, according to the economic settings of the local population.

\subsection{Analysing selling list price trough spatial econometrics and data mining acquisition}

Using spatial econometrics approaches to assess the effect of property quality on housing price has a twenty-year tradition and is considerably evolving during the nineties, especially for the opportunity to use aiding spatial statistical analysis software [8-10]. Nowadays, spatial econometric move forwards from an infant discipline [11] and spatial tests like Moran I, Lagrange Multiplier are now successfully used in Real Estate market analysis [12].

As affirmed by Krause and Bitter [13] spatial dependence and heterogeneity, anisotropic phenomena and boundary effects originate a migration from the simple theory of a non-linear decline of values from the central business district (CBD) to more sophisticated models that take into account polycentric urban regions and other geographic and social heterogeneities.

In the present case, the econometric techniques can provide a significant support to increase the model reliability (i.e. outlier detection) and generate a qualitative spatial representation of selling list prices in urban environments. 
The framework behind this specific approach traced into three different phases. The first one consists in populating the dataset with rental and selling list data. Selling offer prices were retrieved from web property listings concerning apartments that have an overall living area between 55 and $110 \mathrm{~m}^{2}$. All the properties have an ordinary maintenance level and new units or apartments that need to be renovated were not considered for this analysis. The insertion must report some fundamental information like the property address, surface extent and the offer price. Insertions can be collected using both listing website API and web content extractors and geocoded using google map API. The second phase deals mainly with an anomaly detection task that was initially performed removing duplicate or incomplete listings and ended with outliers' detection task. This last process is achieved considering the spatial autocorrelation level of the unit price collected for each single apartment (Monran I) and contribute to identify a large number of units whose selling list differs from what ordinary can be found on the metropolitan area housing market.
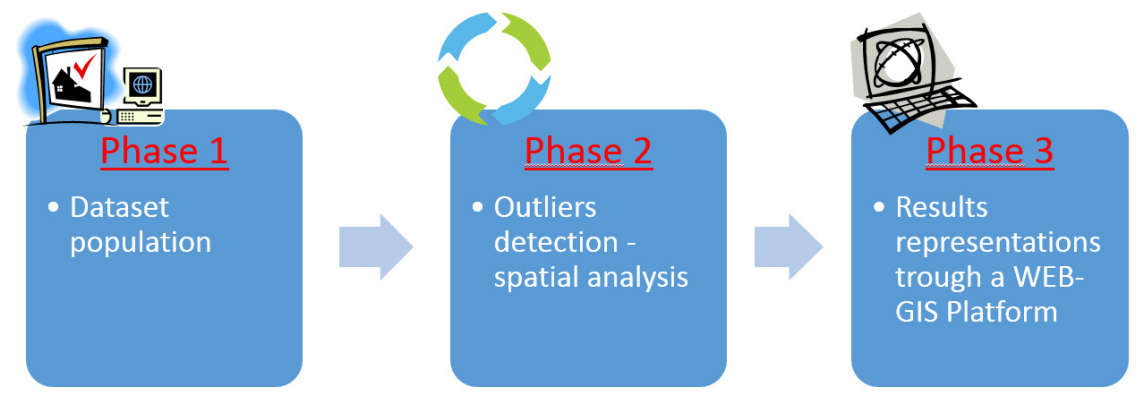

Figure 1: $\quad$ SDSS framework.

During this second phase it was also performed a spatial interpolation of the collected sale listing prices, that will be used to generate the housing affordability analysis. The related maps can be accessed through on-line Google maps engine service or downloading a kmz file on Google Earth.

As shown in Figure 2B, georeferenced offers can generate an interpolation surface that is capable to represent the spatial residential selling lists variation using Euros for square meter as unit of measurement. Experimentally, in the specific case of Milano, it was used a Kriging algorithm that considers the 23 offers nearest to each surface point within a range of 2,500 meters. Once this operation is accomplished, the surface is cropped considering an area of study where the maximum distance between each recorded offer does not exceed 500 or 700 meters, depending on the sample distribution. This general assumption provides a qualitative mechanism to define residential areas boundaries, excluding other destination zones (commercial, industrial developments, public green) that are not covered with this specific analysis. A second more general delimitation is related to the maximum distance from the $\mathrm{CBD}$. The initial dataset acquisition regarded the whole province extension; in order to limit the study just to the metropolitan area boundaries, it was defined a set of maximum distances from 
the city center depending on the total population and conformation of each urban context taken into account. Figure $2 \mathrm{~A}$ shows the boundaries definition process regarding the metropolitan area of Milano. Being the first dataset collected, the results of this delimitation are usually not able to exclude from the analysis some restricted nonresidential areas. It can be possible to work on this restriction by introducing into the system urban plans or other data addressed to insert detailed information regarding the existence and consistency of residential volumes, as described in the conclusions of this work. Once circumscribed the residential area of study, it is possible to investigate the selling list spatial trend (figure 2B). Figure $2 \mathrm{C}$ shows the consistency of the different classes of values (Euros for square meter) resulting from market offers and related to the whole area of study. The advantage of this kind of spatial approach can be appreciated through the comprehension of the map and chart showed, respectively, in Figure 2B and 2C. In this way, even a not expert user is able to understand the complex conformation of any urban housing market.

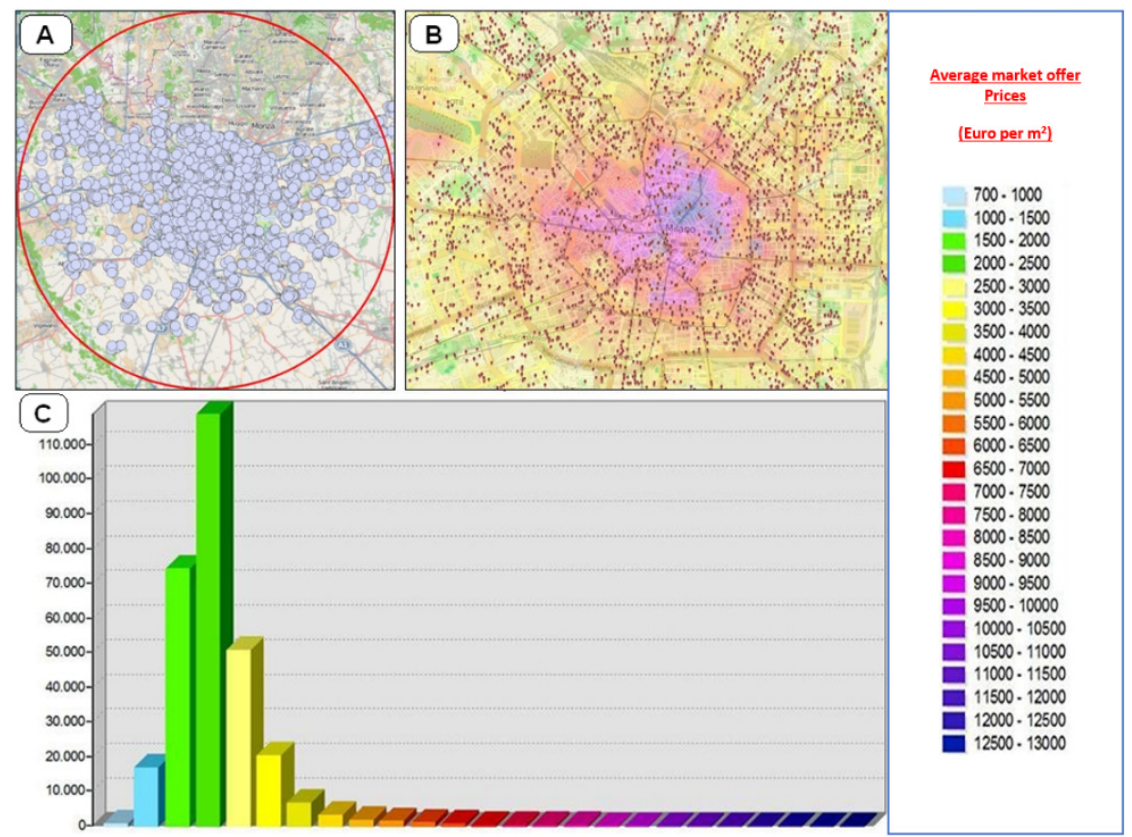

Figure 2: Milano's area of study boundaries (A), housing market offer prices interpolation surface (B) and distribution (C).

It is necessary to put in evidence that offer prices reflect a significant degree of uncertainty if compared to the results that would be obtained by analyzing market prices. Considering the lack of official dataset regarding Italian housing market, this degree of uncertainty can be overshadowed and considered as a fair price to pay to obtain a Spatial Decision Support System that, potentially, can keep track in real-time of the housing market supply. 


\subsection{Measuring the relationship between the local average income and housing offer market prices}

As stated by Mulliner et al. [4] housing affordability is traditionally defined and assessed in terms of economic criteria, but can also has implications for the wider economy and environment. Actually, the relationship between the housing expenditure and household/family income has always been the most common way to define and assess housing economic affordability. This kind of approach can also be found in $19^{\text {th }}$ century studies where "one week pay for one month rent" was considered a fair ratio [2]. A housing affordability criterion is suitable for a general housing market analysis and it is inappropriate for a specific examination of the risk resulting from the purchase of a single housing unit. In fact, considering two distinct residential units within the same market area, characterized, respectively, by the highest and the lowest quality, it is evident that the first one is less affordable for the local community, but not necessarily, it would be a riskier investment.

The Housing Affordability Index (HAI) [15] takes in account the ratio between the effective mortgage rate and the family available income in order to quantify the qualifying income for a home purchase. Following this criteria, a home is considered affordable if the mortgage rate is less than $30 \%$ of the family available income.

Considering the US Department of Housing and Urban Development [18], a fair ratio between house price and household income has not to exceed the $30 \%$ [19]. Moreover, the Median Multiple Indicator rates housing affordability taking into account the ratio between median house price and gross annual median household income. Adopting this approach, the Demographia International Housing Affordability Survey [16] developed an affordability assessment scale from 1 to 5 . Categories from 1 to 3 are considered affordable. The other three categories indicate a moderate (3.1 to 4.0$)$, serious (4.1 to 5.0) and severe (5.1 and over) unaffordability.

Considering the widespread use of Median Multiple Indicator to assess housing affordability, the present research is based on this kind of approach. Taking into account the national average difference between offer and market prices and other related transaction expenses and ordinary buyers' available funds, the available family income requested for an affordable home purchasing has been calculated supposing that the ideal ratio between the $80 \%$ of the average home offer price and the available family income amounts to three.

Starting from this hypothesis, the average selling lists have been spatially analyzed and, by mean of this analysis, it is possible to define the available income needed to buy an apartment with a living area of $55 \mathrm{~m}^{2}$. These assumptions intended to simulate the economic conditions in which it is possible to find a young family that is about to acquire their first home. The designed system is potentially able to perfect this supply spatial study by using different hypothesis and, eventually, improve this kind of affordability analysis by means of official housing market prices. 


\section{Case study: evaluating housing affordability with a spatial approach}

\subsection{Reference data}

As stated previously, the dataset population process regards ten Italian key metropolitan urban areas (Bologna, Cagliari, Firenze, Genova, Milano, Napoli, Palermo, Roma, Torino and Venezia). Currently, the acquired dataset (October 2012) is composed by 24,385 listings sales and 15,642 rental offers. The collected data sample distribution is represented in Figure 3. As shown, the ratio between the analyzed and the whole municipality area can quickly change according to the urban-district situation taken into account. Generally, it can be dependent both on the urban conformation (i.e. presence of parks or other green facilities) and on the local inclination to use the internet to promote home sales.

An initial measurement of the sample reliability level can discern directly from the relationship between the settled population and the number of properties detected. Moreover, in order to get a more detailed picture of the dataset representative capacity, it is also necessary to consider some other metropolitan areas specificity (e.g. presence of historical centers, particularly morphological conformation of the context); elements that can significantly affect the ability to assign an average market selling lists to a given spatial point. For example, apartments on the upper floors are distinguished by a market value significantly higher than ground floors and, sometimes, they can even compose a distinct housing market segment [18].

\subsection{Results}

The obtained results can be read both on a numerical scale and in terms of spatial distribution. In the first case, Figure 3 summarizes the level of accessibility detected following the hypothesis previously stated.

It is evident that in the majority (6/10) of the analyzed metropolitan areas, purchasing an apartment with a living area of $55 \mathrm{~m}^{2}$ turns out to be compatible with an income between 25,000 and 30,000 Euros per year, except for four urban areas (Bologna, Firenze, Genoa, Roma) on which it is needed to carry out some additional considerations. These considerations are related to different specificities: Bologna, for example, despite being a center of small/medium size, is a national reference point regarding academic and cultural sector and also for business activities related to small/medium industrial structures. These custom features and its dominant role in one of Italian richest regions can move the local real estate market center of gravity to a different level of housing purchase accessibility, if compared to other contexts of similar size.

Considering the metropolitan areas of Firenze and Roma, the related internationally recognized historical relevance spread out the real estate market boundaries over the local context. As a proof of that, it can be pointed out that the relationships between the average income (whether provincial or urban) and 


\begin{tabular}{|c|c|c|c|c|c|c|c|c|c|c|}
\hline & Bologna & Cagliari & Firenze & Genova & Milano & Napoli & Palermo & Roma & Torino & $\begin{array}{l}\text { Venezia } \\
\text { Mestre }\end{array}$ \\
\hline Collected Listing Sales (CLS) & 1.113 & 246 & 1.539 & 438 & 5.456 & 2.447 & 443 & 8.272 & 3.370 & 1.061 \\
\hline $\begin{array}{l}\text { Province Population } \\
\text { (2012) - (PP) }\end{array}$ & 976.053 & 549.893 & 972.232 & 853.939 & 3.035 .443 & 3.053 .247 & 1.242 .560 & 3.995 .250 & 2.243 .382 & 846.275 \\
\hline $\begin{array}{l}\text { Municipality Population } \\
\text { (2012) - (MP) }\end{array}$ & 371.151 & 149.343 & 191.621 & 584.644 & 1.240 .173 & 961.106 & 656.829 & 2.614 .263 & 869.312 & 260.856 \\
\hline CLS / MP & 0,002999 & 9,001647 & 0,008031 & 0,000749 & 0,004399 & 0,002546 & 0,000674 & 0,003164 & 0,003877 & 0,004067 \\
\hline $\begin{array}{c}\text { Province Median Income } \\
\text { (2010) - (PMI) }\end{array}$ & $25.828,00$ & $23.036,00$ & $24.520,00$ & $24.863,00$ & $29.789,00$ & $22.355,00$ & $22.554,00$ & $27.934,00$ & $24.307,00$ & $22.980,00$ \\
\hline $\begin{array}{c}\text { Municipality Median Income } \\
(2010)-(\mathrm{MMI})\end{array}$ & $28.719,00$ & $27.993,00$ & $27.822,00$ & $25.238,00$ & $35.751,00$ & $25.884,00$ & $25.363,00$ & $30.284,00$ & $26.300,00$ & $25.396,00$ \\
\hline $\begin{array}{l}\text { Requested Avaiable Median } \\
\text { Family Income (RAMFI) - } \\
\text { (EUR/YEAR) }\end{array}$ & Bologna & Cagliari & Firenze & Genova & Milano & Napoli & Palermo & Roma & Torino & $\begin{array}{l}\text { Venezia } \\
\text { Mestre }\end{array}$ \\
\hline$<22500$ EUR/YEAR & $<0,01 \%$ & $3,21 \%$ & $0,00 \%$ & $1,88 \%$ & $4,47 \%$ & $5,07 \%$ & $6,95 \%$ & $0,42 \%$ & $8,77 \%$ & $7,73 \%$ \\
\hline $22500-25000$ & $0,80 \%$ & $22,17 \%$ & $0,00 \%$ & $8,61 \%$ & $22,40 \%$ & $22,80 \%$ & $20,94 \%$ & $3,66 \%$ & $37,22 \%$ & $27,58 \%$ \\
\hline $25000-30000$ & $23,11 \%$ & $46,73 \%$ & $7,86 \%$ & $16,73 \%$ & $35,17 \%$ & $35,47 \%$ & $65,51 \%$ & $13,30 \%$ & $38,40 \%$ & $41,07 \%$ \\
\hline $30000-35000$ & $59,70 \%$ & $20,29 \%$ & $29,85 \%$ & $11,52 \%$ & $18,91 \%$ & $14,09 \%$ & $6,38 \%$ & $17,48 \%$ & $12,48 \%$ & $5,87 \%$ \\
\hline $35000-40000$ & $12,29 \%$ & $7,20 \%$ & $49,32 \%$ & $7,05 \%$ & $8,93 \%$ & $7,58 \%$ & $0,21 \%$ & $16,99 \%$ & $2,09 \%$ & $3,03 \%$ \\
\hline $40000-50000$ & $<0,01 \%$ & $0,40 \%$ & $12,27 \%$ & $21,24 \%$ & $5,33 \%$ & $5,84 \%$ & $<0,01 \%$ & $28,77 \%$ & $0,78 \%$ & $4,16 \%$ \\
\hline $50000-60000$ & $<0,01 \%$ & $<0,01 \%$ & $<0,01 \%$ & $14,71 \%$ & $2,03 \%$ & $2,94 \%$ & $<0,01 \%$ & $11,28 \%$ & $0,20 \%$ & $5,56 \%$ \\
\hline $60000-70000$ & $<0,01 \%$ & $<0,01 \%$ & $<0,01 \%$ & $11,32 \%$ & $1,29 \%$ & $2,67 \%$ & $<0,01 \%$ & $4,41 \%$ & $0,07 \%$ & $4,20 \%$ \\
\hline $70000-80000$ & $<0,01 \%$ & $<0,01 \%$ & $<0,01 \%$ & $4,47 \%$ & $0,57 \%$ & $2,43 \%$ & $<0,01 \%$ & $2,17 \%$ & $<0,01 \%$ & $0,49 \%$ \\
\hline $80000-90000$ & $<0,01 \%$ & $<0,01 \%$ & $<0,01 \%$ & $2,31 \%$ & $0,38 \%$ & $0,98 \%$ & $<0,01 \%$ & $0,67 \%$ & $<0,01 \%$ & $0,16 \%$ \\
\hline $90000-100000$ & $<0,01 \%$ & $<0,01 \%$ & $<0,01 \%$ & $0,17 \%$ & $0,25 \%$ & $0,14 \%$ & $<0,01 \%$ & $0,34 \%$ & $<0,01 \%$ & $0,08 \%$ \\
\hline $100000-125000$ & $<0,01 \%$ & $<0,01 \%$ & $<0,01 \%$ & $<0,01 \%$ & $0,18 \%$ & $<0,01 \%$ & $<0,01 \%$ & $0,40 \%$ & $<0,01 \%$ & $0,07 \%$ \\
\hline $125000-150000$ & $<0,01 \%$ & $<0,01 \%$ & $<0,01 \%$ & $<0,01 \%$ & $0,07 \%$ & $<0,01 \%$ & $<0,01 \%$ & $0,09 \%$ & $<0,01 \%$ & $0,01 \%$ \\
\hline $150000-200000$ & $<0,01 \%$ & $<0,01 \%$ & $<0,01 \%$ & $<0,01 \%$ & $0,01 \%$ & $<0,01 \%$ & $<0,01 \%$ & $0,02 \%$ & $<0,01 \%$ & $<0,01 \%$ \\
\hline Minimum RAMFI & $18.162,36$ & $12.639,46$ & $32.897,19$ & $19.556,04$ & $16.123,54$ & $11.747,00$ & $10.222,82$ & $14.423,76$ & $16.805,04$ & $13.168,27$ \\
\hline Maximum RAMFI & $44.958,16$ & $44.346,78$ & $70.408,87$ & $98.831,13$ & $165.567,23$ & $95.292,26$ & $35.255,16$ & $367.700,00$ & $63.057,66$ & $136.999,68$ \\
\hline Standard Deviation & $3.560,14$ & $4.251,31$ & $5.998,86$ & $16.339,91$ & $10.725,18$ & $12.517,90$ & $5.296,40$ & $13.861,00$ & $5.124,95$ & $11.051,95$ \\
\hline Mean RAMFI & $32.188,92$ & $27.704,28$ & $43.010,76$ & $43.063,44$ & $28.765,06$ & $29.238,85$ & $20.849,50$ & $40.988,19$ & $24.060,86$ & $27.192,05$ \\
\hline PMI / Mean RAMFI & $19,76 \%$ & $16,85 \%$ & $42,99 \%$ & $42,26 \%$ & || $-3,56 \%$ & $23,54 \%$ & $-8,18 \%$ & $31,85 \%$ & $\mid-1,02 \%$ & $15,49 \%$ \\
\hline MMI / Mean RAMFI & $10,78 \%$ & $\mid-1,04 \%$ & $35,31 \%$ & $41,39 \%$ [ & $\mid-24,29 \%$ & $11,47 \%$ & $21,65 \%$ & $26,12 \%$ & $-9,31 \%$ & $6,61 \%$ \\
\hline
\end{tabular}

Figure 3: Dataset consistency and fraction of metropolitan residential zones where an investment in an apartment with a living area of $55 \mathrm{~m}^{2}$ is considered affordable.

the average income required to purchase (PMI/Mean Ratio and MMI/Mean Ratio) are, respectively, the second and the third highest in the sample. The highest ratio between these two parameters is the one recorded in Genova's metropolitan area, where the particular morphology of the region significantly limits urban development. This situation has historically reduced the option to place new buildings on the market. Environmental aspects can also have a significant influence: Figure 4a shows the substantial difference between the purchase affordability on interior and coastal areas.

Through a general analysis of the relationship between the available family income needed to purchase an apartment with a living space of $55 \mathrm{~m}^{2}$ and, respectively, the median income recorded in the province (PMI) and/or the central metropolitan context (MMI), it is possible to make some interesting considerations. Milano, Palermo and Torino results the metropolitan areas where home purchasing is more accessible to local community. Within these areas, the recorded average income allows an affordable local home purchasing. Conversely, considering the reasons previously stated, Firenze, Genova, Roma and Naples resulted the metropolitan areas where it was recorded the highest unaffordability level. This result is in line with the last report on regional residential market published by the Italian national market observatory. The report states that 
Genova, Firenze, Napoli and Roma are respectively the capitals of the four most unaffordable regions of Italy [3].

A final consideration regards the maximum, minimum offer price recorded and the associated standard deviation parameters. Taking into account the sample dimension and the fact that this research is focused on listing prices, the first two parameters have a scarce importance (their consistency cannot lead to any practical consideration) and can be considered not influent in selling list formation. In urban environments, the standard deviation can assume a considerable importance where the values distribution is not affected by specific morphological characteristics (i.e. where the values tend to increase inversely to the distance from the CBD or the Historical District). Within this logic, the low standard deviation values collected in Firenze, Milano, Palermo and Torino seems to demonstrate a good reliability of the acquired dataset. Different considerations can be made for those contexts where the qualitative localization factors appear to be arranged randomly in space. For example, Cagliari municipality stands on seven hills that can overlook the sea and offer a high quality level of panoramic views. For these reasons, residential quality and the associated price can change significantly within a short distance. In such cases, a high standard deviation value is an indicator of an inadequate sample reliability, incapable of measuring sudden changes in the urban space. Up to this point, we have carried out key findings about the obtained numerical and quantitative results. These results allow to recognize some majorly noteworthy aspects regarding the overall study, but can be interpreted only by housing market expert users. Sometimes they can even be misleading respect to reality and extremely limited if compared to what can be revealed by a spatial approach. For example, analyzing the numerical results obtained studying the metropolitan area of Venezia/Mestre (Figure 3), it seems that this specific housing market can be considered affordable if compared to the other examined cities. In fact, there is a reasonable level of income distribution and a relationship between metropolitan/provincial income and selling lists that is slightly higher than the average of the overall analyzed metropolitan areas. Everything seems to suggest the occurrence of an ordinary national market condition in which stands, for example, a small-medium sized metropolitan area. Results are, not so different, for example, from those obtained for the metropolitan area of Cagliari.

Nevertheless, if we consider the same results from a spatial point of view (Figure 4c), it is possible to observe the globally known reality of an absolutely outstanding urban area, where real estate values reach the top on the insular context and do not allow purchase accessibility to local ordinary citizens. This market condition, however, is balanced by the presence of Mestre where housing market is easily accessible and enables the local community to purchase or rent a house. The same easy sensing perceiving of property purchase accessibility is manifested on the spatial representation of the results related to other urban areas. For example, taking into account Milano and Roma (Figure 5), the housing purchase difficulty in Roma and the different situation in Milano (where a more healthy housing market is able to meet the needs of low range income classes) are immediately appreciable. 


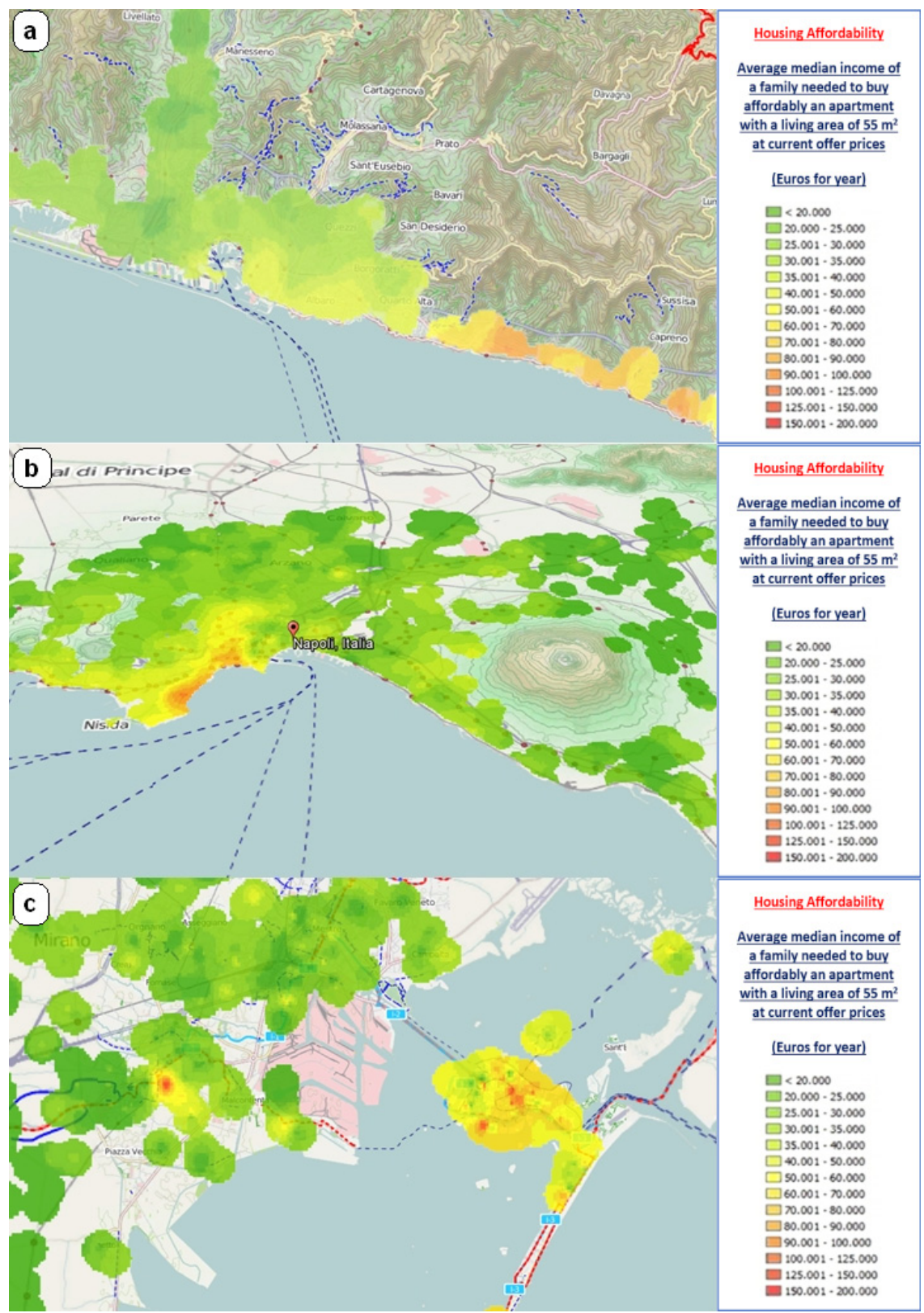

Figure 4: Housing affordability from offer prices in Genova (a), Napoli (b), Venezia (c): qualitative spatial assessment of the average median income required to buy affordably an apartment with a living area of $55 \mathrm{~m}^{2}$ at October 2012 . 


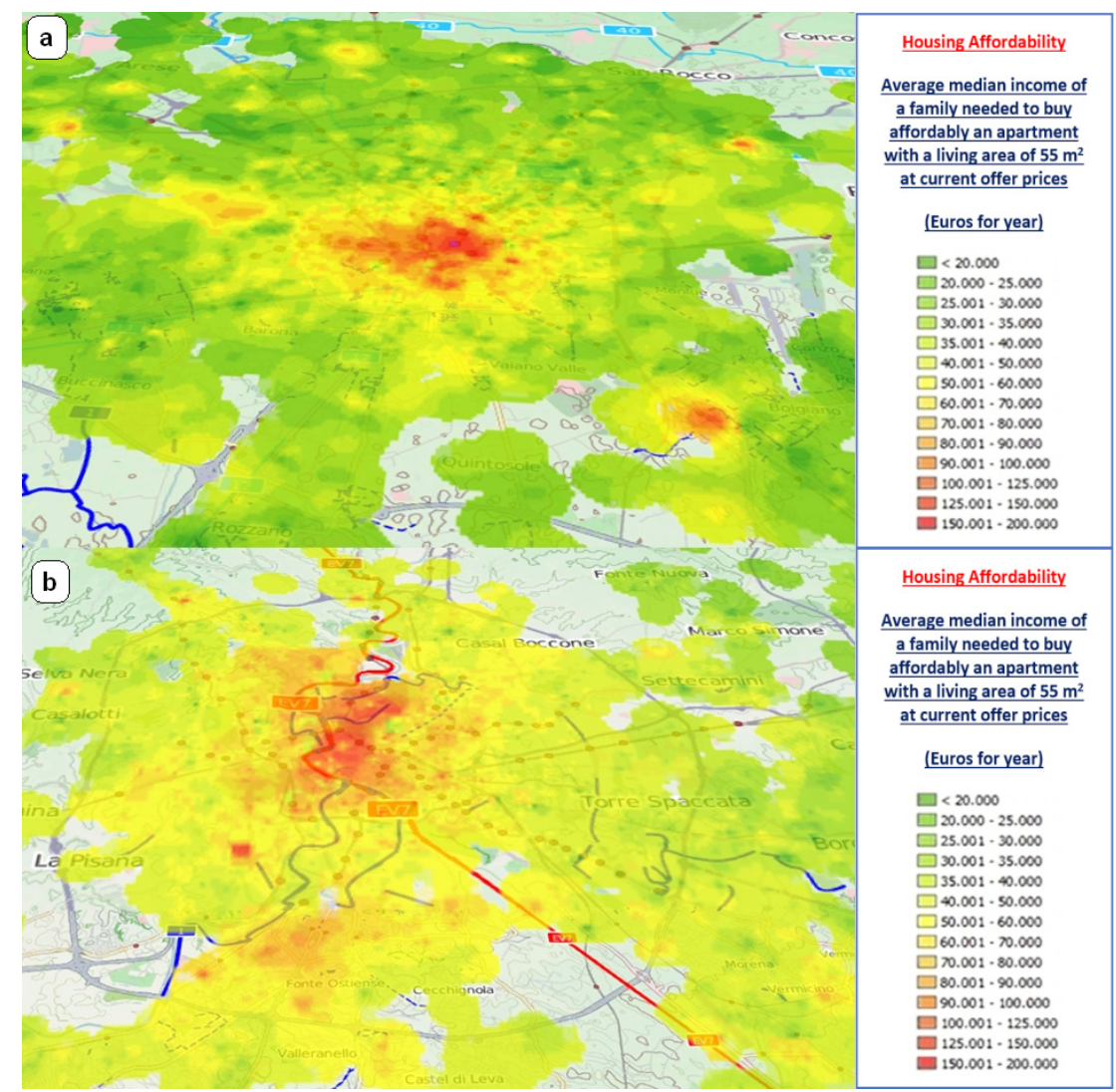

Figure 5: Housing affordability from offer prices in Milano (a) and Roma (b): qualitative spatial assessment of the average median income required to buy affordably an apartment with a living area of $55 \mathrm{~m}^{2}$ at October 2012.

Even in a multifaceted metropolitan area like Napoli (Figure 4b), the housing market can be explained in a clear and straightforward way through the related housing affordability heat map: starting from a central setting, where the market is inaccessible for most of the citizen, housing affordability increases along the inland areas. Although distant from the city center, coastal lands are also characterized by an extremely low purchase accessibility level.

These simple considerations clearly point out that, despite the actual scarce use in Real Estate market analysis, spatial analysis is essential for an effective affordability market analysis. It can be able to return comprehensive and updated knowledge of market dynamics in order to make it more transparent to investors and city administrators. In addition, if we consider that housing property investment is often the largest financial asset of an ordinary citizen, this kind of approach can also effectively assess the impact of different territorial planning policies options on citizens' savings. 


\section{Conclusions and future improvements}

Despite the current gaps in the adopted technical methodology, with a particular reference to the spatial analysis approach, results are in line with the outcomes expressed by official reports based on market transactions. These gaps are generally connected to the difficulties in adopting spatial analysis approaches to a singular typology of market like the Real Estate one, where two properties are never identical and demand and supply are considered casual factors. On this matter, the development of an historical dataset can be able to evolve the reliability of the results, especially in those areas characterized by a low dataset density. Spatial analysis can also be implemented both with a more accurate data acquisition (i.e. building age and conditions) and through the spatial overlay of the acquired data in grid cells. The definition of the size and shape of these cells is a very complex operation and cannot be disjointed from the specific urban conformation and the localization of externalities. Another more concrete improvement consists in perfecting the delimitation of residential areas involved in the study. Actually, these areas are defined by generating boundaries of different size around the collected samples. This operation appears inaccurate if compared with the potential results that can be achieved using the specific zoning plan. Such implementation can be accomplished in the short term as, after the adoption of INSPIRE directive [19], Italian and other European municipalities seem to be more willing to make urban plans available in digital formats. In this respect, a first investigation, involving the Honolulu (Hawaii, USA) metropolitan area, has already been accomplished by restricting the study to the residential boundaries reported in Honolulu's urban plan (Figure 6).

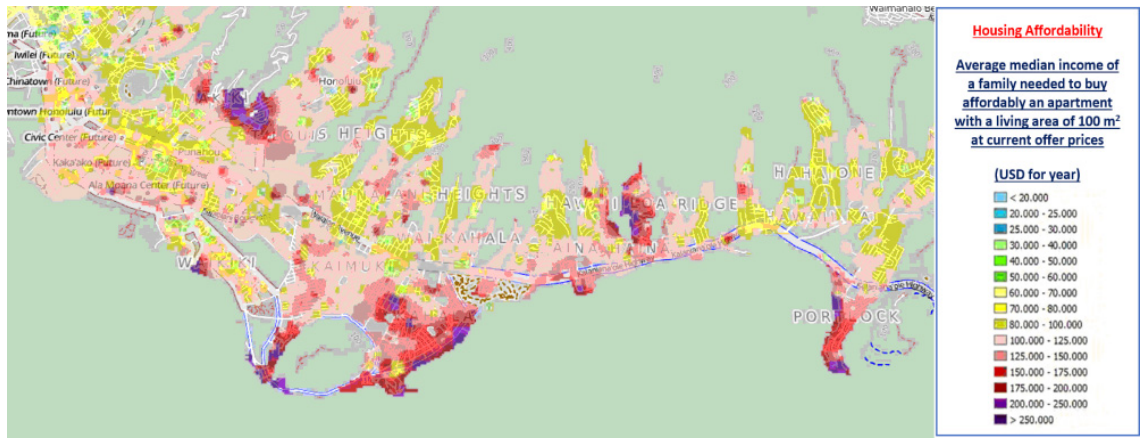

Figure 6: Housing affordability from offer prices in Honolulu (HI): qualitative spatial assessment of the average median income required to buy affordably an apartment with a living area of $100 \mathrm{~m}^{2}$ at January 2013.

\section{References}

[1] Gan, Q. \& Hill, R. J., Measuring housing affordability: Looking beyond the median, Journal of Housing Economics, 18, pp. 115-125, 2009.

[2] Residential Update, February 4, 2012, http://www.appraisalinstitute.org [accessed October 23, 2014]. 
[3] OMI, Rapporto Immobiliare 2013. Il settore residenziale, 2013. http:/www.agenziaentrate.gov.it/wps/wcm/connect/daa7ce004f9dc23f867 8879065056eba/RI_2013_Quadro_generale.pdf?MOD=AJPERES\&CAC $\mathrm{HEID}=\mathrm{daa} 7 \mathrm{ce} 004 \mathrm{f} 9 \mathrm{dc} 23 \mathrm{f} 8678879065056 \mathrm{eba}$ [accessed October 23, 2014].

[4] Mulliner, E., Smallbone, K. \& Maliene, V., An assessment of sustainable housing affordability using a multiple criteria decision making method, Omega, 41(2), pp. 270-279, 2013.

[5] Bank of Italy, Supplements to the Statistical Bulletin. Sample Surveys. Italian Housing Market Survey, Short-term Outlook, October 2013.

[6] Openshaw, S., Building automated Geographical Analysis and Explanation Machines, Geocomputation, aPrimer, eds. P.A. Longley, S.M. Brooks, R. McDonnell, B. Macmillan, John Wiley and Sons, Chichester, 1998.

[7] Murgante, B. \& Borruso, G., Cities and Smartness: A Critical Analysis of Opportunities and Risks, Lecture Notes in Computer Science, vol. 7973, pp. 630-642, Springer-Verlag, Berlin Heidelberg, 2013.

[8] Goodman, A.C., Hedonic prices, price indices and housing markets, Journal of Urban Economics, 5(4), 471-484, 1978.

[9] Li, M. \& Brown, H., Micro-neighborhood externalities and hedonic housing prices, Land Economics, 56(2), 125-141, 1980.

[10] Anselin, L., Spatial econometrics: Methods and models. Kluwer, Academic: Dordrecht, 1988.

[11] Goodchild M.F., Advances in Spatial Econometrics. Methodology, Tools and Applications, eds. Anselin, L., Florax, R.J.G.M., \& Rey S.J., p. 3, Springer-Verlag, Berlin Heidelberg, 2013.

[12] Osland, L., An application of spatial econometrics in relation to hedonic house price modelling, Journal of Real Estate Research, 32(3), 289-320, 2010.

[13] Krause, A. \& Bitter. C., Spatial econometrics, land values and sustainability: Trends in real estate valuation research, Cities, 29 (2), 2012.

[14] Cox, W., Pavletich, H., 8th Annual Demographia International Housing Affordability Survey: 2012 Ratings for Metropolitan Markets, p. 1, 2012.

[15] US Department of Housing and Urban Development, http://portal.hud.gov/hudportal/HUD [accessed October 23, 2014].

[16] http://www.realtor.org/topics/housing-affordability-index/data [accessed October 23, 2014].

[17] Linneman, P., Megbolugbe, I. F., Housing Affordability: Myth or Reality? Wharton Real Estate Center, University of Pennsylvania, 1992.

[18] Argiolas, M., Selling lists, data mining and spatial econometrics: A complementary approach to study real estate market dynamics, UDMS Annual 2013, Taylor \& Francis Group, London, 2013.

[19] INSPIRE: Directive of the European Parliament and of the Council establishing an Infrastructure for Spatial Information in the European Community (2007), http://www.ec-gis.org/inspire/ [accessed October 23, 2014] 